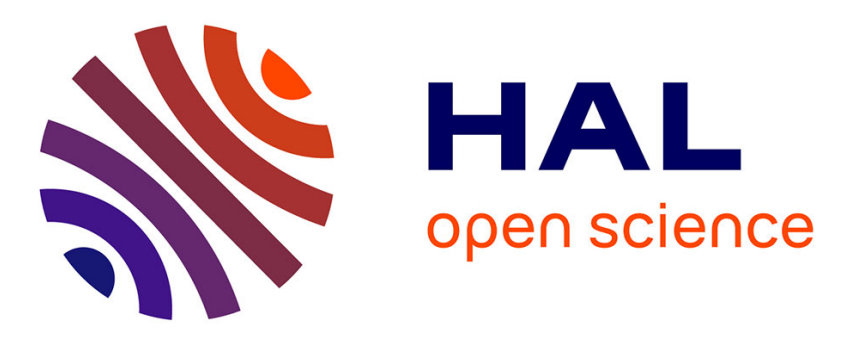

\title{
A Robust Hybrid Current Control for Permanent Magnet Synchronous Motor Drive
}

Mohamed Kadjoudj, Mohamed Benbouzid, Chawki Ghennai, Demba Diallo

\section{To cite this version:}

Mohamed Kadjoudj, Mohamed Benbouzid, Chawki Ghennai, Demba Diallo. A Robust Hybrid Current Control for Permanent Magnet Synchronous Motor Drive. IEEE Transactions on Energy Conversion, 2004, 19 (1), pp.109-115. hal-01048908

\section{HAL Id: hal-01048908 https://hal.science/hal-01048908}

Submitted on 25 Jul 2014

HAL is a multi-disciplinary open access archive for the deposit and dissemination of scientific research documents, whether they are published or not. The documents may come from teaching and research institutions in France or abroad, or from public or private research centers.
L'archive ouverte pluridisciplinaire HAL, est destinée au dépôt et à la diffusion de documents scientifiques de niveau recherche, publiés ou non, émanant des établissements d'enseignement et de recherche français ou étrangers, des laboratoires publics ou privés. 


\title{
A Robust Hybrid Current Control for Permanent Magnet Synchronous Motor Drive
}

\author{
Mohamed Kadjoudj, Mohamed Benbouzid, Senior Member, IEEE \\ Chawki Ghennai and Demba Diallo, Member, IEEE
}

\begin{abstract}
Recently, the Permanent Magnet Synchronous Motor (PMSM) find a widespread utilization in modern adjustable AC drives. This is achieved by using current controlled Voltage Source Inverter (VSI) systems. Because of its ease implementation, fast current control response and inherent peak current limiting capability, hysteresis current control is considered as the simplest technique used to control the motor currents for AC machines. On the other hand, the ramp comparator controller has some advantages, such as limiting maximum inverter switching frequency to the carrier triangular waveform frequency and producing well-defined harmonics. In order to take advantage of the position features of both these two controllers, this paper presents the design and software implementation of a hybrid current controller. The proposed intelligent controller is a simultaneous combination and contribution of the hysteresis current controller and the ramp comparator. Comparisons using simulations on a 0.9-kW PMSM confirm that the proposed hybrid current controller gives better performance and has the advantage of conceptual simplicity. In particular, harmonic spectra of the stator current, obtained by using a fast Fourier transform, are used for comparison purposes.
\end{abstract}

Index Terms-PMSM, robustness, hysteresis controller, ramp comparator, hybrid controller.

\section{NOMENCLATURE}

$\begin{array}{ll}s,(r) & =\text { stator (rotor) index; } \\ d, q & =\text { synchronous reference frame index; } \\ V & =\text { voltage; } \\ I & =\text { current; } \\ \phi_{f} & =\text { permanent magnet flux; } \\ T_{e}, & =\text { electromagnetic torque; } \\ T_{l} & =\text { load torque; } \\ R & =\text { resistance; } \\ L & =\text { inductance; } \\ \omega_{r} & =\text { angular speed; } \\ \theta & =\text { rotor position; } \\ f & =\text { viscosity coefficient; }\end{array}$

M. Kadjoudj and C. Ghennai are with the Electrical Engineering Department, University of Batna, Algeria.

M.E.H. Benbouzid and D. Diallo are with the Centre de Robotique, d'Electrotechnique et d'Automatique (CREA) of the University of Picardie Jules Verne at Amiens, 7, Rue du Moulin Neuf, 80000 Amiens, France (email: m.benbouzid@ieee.org; ddiallo@ieee.org).

$$
\begin{array}{ll}
J & =\text { rotor inertia; } \\
n_{p} & =\text { pole pair number; } \\
K_{T} & =K_{T}=3 n_{p} \phi_{f} / 2 ; \\
p & =\text { derivative operator. }
\end{array}
$$

\section{INTRODUCTION}

Permanent Magnet Synchronous Motor (PMSM) drives are today gradually replacing classic dc drives in a large number of industrial applications, taking full advantage of key features of PM motors, such as compactness, efficiency, robustness, reliability, and shape adaptation to the working environment [1-2].

Substantial development efforts have been devoted to the application of various classes of robust control techniques in order to exploit the efficiency and extremely fast dynamic capabilities of the PMSM. More specifically, there have been several papers describing applications of various strategies of speed and current controllers [3-10]. The closed loop vector control technique is used for the PMSM to obtain the equivalent performance of a separately excited dc motor. Such technique is implemented using both current and speed controllers. A typical closed loop vector control scheme for the PMSM drive is shown in Fig. 1.

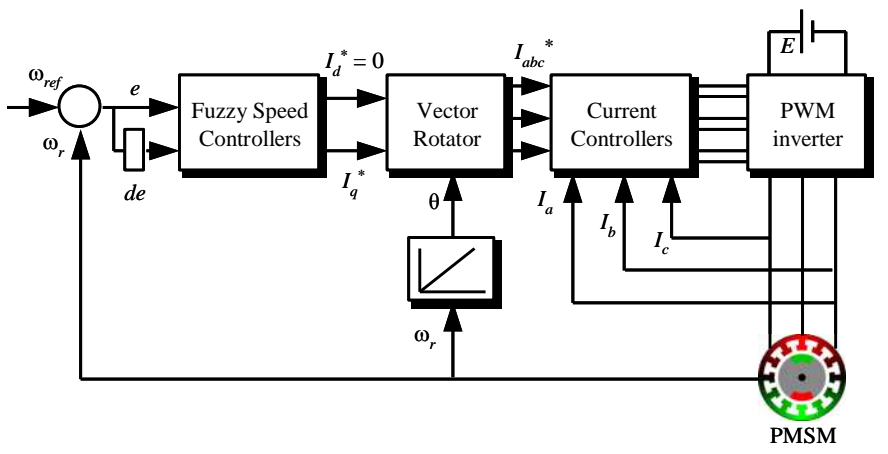

Fig. 1. PMSM control block diagram.

The most common strategies of current controllers can be classified as hysteresis and ramp comparator controllers [11]. Each scheme has its advantages and drawbacks with regard to insensitivity to parameters variations, accuracy, robustness and dynamic response over the entire speed range. The advantages of hysteresis current controllers lie in their simplicity and their providing fast responses and good accuracy, because they act quickly. However, the switching frequency may vary widely during the fundamental period, 
resulting in irregular inverter operations. This is mainly due to the interference between the three-phase commutations. Thus, the actual current waveform is not determined by the hysteresis current control, the current slope may vary widely and current peaks may significantly exceed the limits of hysteresis bands. The ramp comparator controller has the advantages of limiting the maximum inverter switching frequency to the carrier triangular waveform frequency and producing well-defined harmonics. On the other hand, magnitude and phase errors in the line currents may be produced. Furthermore, multiple crossings of the ramp may become a serious problem when the current error time rate of change exceeds that of the ramp. A third strategy of current controllers is that of predictive controllers. The next switching-state vector for achieving good current tracking control is determined via prediction and optimization. The lookup table method is usually utilized to realize this kind of switching control approach. The current control response might be slower than other types of current controllers due to the extra processing time [12].

Up to now, most of the research [13-18] has been performed to allow the hysteresis current-controlled PWM inverter to have a constant switching frequency. Recently, in [19], a robust hysteresis current control with nonconstant switching frequency has been proposed. However, the detailed investigation and the way to overcome the limitations of various current controllers at variable-speed drive applications have not yet been reported.

Therefore, to deal with the above-cited problems and to take advantage of the position features of both the hysteresis and ramp controllers, this paper proposes a hybrid current control strategy to follow up the comparative study reported in [20], where a detailed comparison between hysteresis and ramp controllers provide the clue to develop a hybrid current controller. The proposed controller is a combination of hysteresis and ramp comparator controllers. Contrary to the hybrid controller proposed in [20], where the hysteresis current controller is used for high-speed operations and the ramp comparator scheme is used for low speed operations, the proposed controller has the particularity of a simultaneous combination of the above controllers in order to achieve better performance over the entire speed range.

Simulation results on a $0.9-\mathrm{kW}$ PMSM are presented to highlight the advantages and the simplicity of the proposed hybrid current controller. In particular, harmonic spectra of the stator current, obtained using a fast Fourier transform, are presented for comparison purposes.

\section{PMSM MODELING}

The voltage equations in a synchronous reference frame can be presented by the following equation.

$$
\left[\begin{array}{l}
V_{d} \\
V_{q}
\end{array}\right]=\left[\begin{array}{cc}
R_{s}+p L_{d} & -\omega_{r} L_{q} \\
\omega_{r} L_{d} & R_{s}+p L_{q}
\end{array}\right]\left[\begin{array}{c}
I_{d} \\
I_{q}
\end{array}\right]+\left[\begin{array}{c}
0 \\
\omega_{r} \phi_{f}
\end{array}\right]
$$

From the above equations, the developed torque can be written as
$T_{e}=K_{T} I_{q}+\frac{K_{T}}{\phi_{f}}\left(L_{d}-L_{q}\right) I_{d} I_{q}$

and the motor dynamics can be simply described by

$$
\frac{J}{n_{p}} \frac{d \omega_{r}}{d t}+\frac{f}{n_{p}} \omega_{r}=T_{e}-T_{l}
$$

Using the field orientation concept, assumption can be made that the $d$-axis current is controlled to be zero. The second term of equation (2) therefore becomes negligible. The reduced dynamic model of the PMSM is therefore given by the following set of equations.

$$
\left\{\begin{array}{l}
\frac{d I_{q}}{d t}=\frac{1}{L_{q}} V_{q}-\frac{R_{s}}{L_{q}} I_{q}-\frac{\phi_{f}}{L_{q}} \omega_{r} \\
\frac{J}{n_{p}} \frac{d \omega_{r}}{d t}=K_{T} I_{q}-\frac{f}{n_{p}} \omega_{r}-T_{l} \\
\frac{d \theta}{d t}=\omega_{r}
\end{array}\right.
$$

The above system resolution provides the output variables $\left(I_{q}, \omega_{r}, \theta, I_{d}, T_{e}\right)$ of the PMSM block.

\section{CURRENT CONTROLLER DESIGN}

\section{A. Hysteresis Current controller}

In the vector control scheme, the current controller has direct influence on the drive performance and its design requires special considerations. The basic requirements for the current controllers are low harmonics to reduce losses, low torque pulsation, low noise in the motor, and fast response in order to provide high dynamic performance [20-21].

The logic operation of the voltage source inverter under current control is reported in table 1 . There are eight switch combinations for the six switches of the inverter. The voltage vectors corresponding to the active states are shown in Fig. 2 The six commands $V_{1}$ to $V_{6}$ correspond to active voltage vectors; the remaining two $V_{0}$ and $V_{7}$ correspond to the zero voltage vectors [20], [22-23].

In the hysteresis current controller of Fig. 3, load currents $I_{a}, I_{b}$ and $I_{c}$ are respectively forced to follow reference currents $I_{\text {aref }}, I_{\text {bref }}$ and $I_{\text {cref }}$ within a hysteresis band by the switching action of the inverter.

The upper and lower bounds of the hysteresis band are set for the motor current, and the hysteresis controller logic control can be described according to the following rules.

Rule A: For $I_{\text {aref }}>0$ : Th4 = 0,

\begin{tabular}{|c|c|c|}
\hline If & $I_{a}>I_{\text {aref }}+\Delta I$ & Then \\
\hline $\begin{array}{l}\text { Else if } \\
\text { Else }\end{array}$ & $\begin{array}{l}I_{a}<I_{\text {aref }}-\Delta I \\
\text { no change. }\end{array}$ & Then \\
\hline
\end{tabular}

$$
\begin{aligned}
& \text { If } I_{a}>I_{\text {aref }}+\Delta I \quad \text { Then } \text { Th1 }=0 \text {, } \\
& \text { Else if } I_{a}<I_{\text {aref }}-\Delta I \quad \text { Then } \mathrm{Th} 1=1 \text {, } \\
& \text { Else no change. }
\end{aligned}
$$

Rule B: For $I_{\text {aref }}<0$ : Th1 $=0$, 
Table 1. VSI conduction modes.

\begin{tabular}{|c|c|c|c|c|c|c|c|}
\hline \multirow{2}{*}{$\begin{array}{c}\text { State } \\
\text { Order }\end{array}$} & \multicolumn{2}{|c|}{$\begin{array}{c}\text { Legs } \\
\text { "Phase 1" }\end{array}$} & \multicolumn{2}{c|}{$\begin{array}{c}\text { Legs } \\
\text { "Phase 2" }\end{array}$} & \multicolumn{2}{c|}{$\begin{array}{c}\text { Legs } \\
\text { "Phase 3" }\end{array}$} & \multirow{2}{*}{$\begin{array}{c}\text { Operation } \\
\text { Modes }\end{array}$} \\
\cline { 2 - 7 } & Th1 & Th4 & Th3 & Th6 & Th5 & Th2 & \\
\hline$V_{0}$ & 0 & 1 & 0 & 1 & 0 & 1 & Freewheeling \\
\hline$V_{1}$ & 1 & 0 & 0 & 1 & 0 & 1 & Active \\
\hline$V_{2}$ & 0 & 1 & 1 & 0 & 0 & 1 & Active \\
\hline$V_{3}$ & 1 & 0 & 1 & 0 & 0 & 1 & Active \\
\hline$V_{4}$ & 0 & 1 & 0 & 1 & 1 & 0 & Active \\
\hline$V_{5}$ & 1 & 0 & 0 & 1 & 1 & 0 & Active \\
\hline$V_{6}$ & 0 & 1 & 1 & 0 & 1 & 0 & Active \\
\hline$V_{7}$ & 1 & 0 & 1 & 0 & 1 & 0 & Freewheeling \\
\hline
\end{tabular}

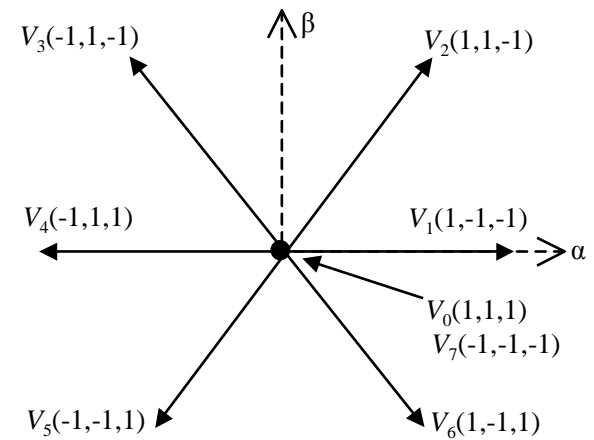

Fig. 2. Switching states under current controller.

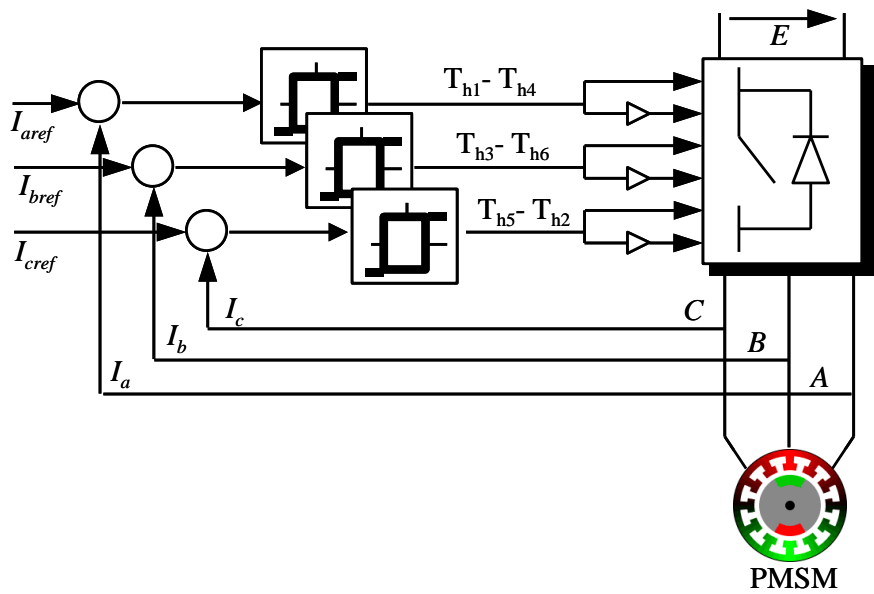

Fig. 3. Hysteresis current controller.

In a basic implementation of the hysteresis current controller, the switching signals are derived from the comparison of the current error with a fixed hysteresis band. Although it is simple and extremely robust, the control technique suffers several drawbacks, mainly the variation of the modulating frequency of the power converter. Generally speaking, a three-phase VSI does not work properly if controlled by three independent hysteresis loops. This is due to the inherent coupling between the inverter three phases. Figure 3 shows that the use of individual controllers provides mutual interactions of the controllers and current errors equal to twice the imposed tolerance band $\Delta I$.

\section{B. Ramp Comparator Controller}

The PMSM is generally driven by using current controlled VSI. In the ramp comparator scheme, the motor currents are sensed and compared to the reference currents, which are generated from the field-oriented controller. The ramp comparator controller is based on the following control logic rules.

Rule A: $\quad$ For $I_{\text {aref }}>0$,

$$
\text { If } V_{a}-V_{t r}>0 \text { Then Th4=1 Else Th1 } 1 \text {. }
$$

Rule B: For $I_{\text {aref }}<0$

$$
\text { If } V_{a}-V_{t r}>0 \text { Then Th1=1 Else Th4 }=1 \text {. }
$$

In Figure 4, the error signals are compared to a triangular waveform to produce inverter constant frequency PWM drive signals. The switching frequency is limited to that of the triangular waveform and this represents the main advantage of the ramp comparator controller. However, inherent tracking amplitude and phase errors are the main drawbacks of this technique. Although good performances can be obtained for low and medium speeds, the amplitude and phase errors are introduced in the motor line currents. These amplitude and phase errors become unacceptable for high performance drive applications.

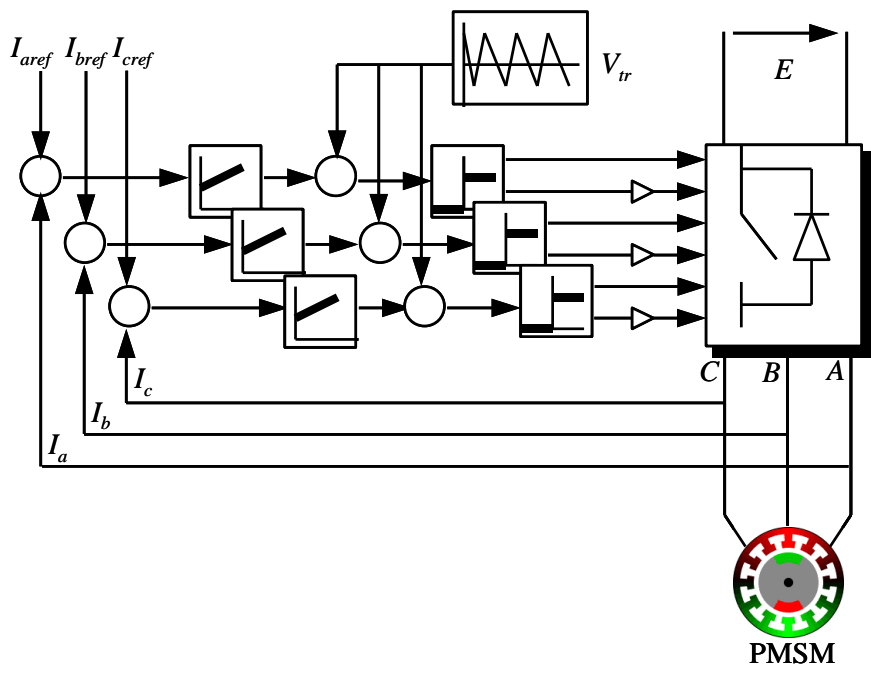

Fig. 4. Ramp comparator controller.

\section{Hybrid Current Controller}

In order to overcome the previously mentioned drawbacks of the hysteresis and ramp comparator controllers, a hybrid controller is proposed and implemented. The schematic diagram of the controller is shown in Fig. 5. The proposed hybrid current controller consists in the simultaneous use of the hysteresis and the ramp comparator controllers without a switching mode level between the hysteresis and ramp comparator modes.

The principle of the proposed hybrid current controller is based on the superposition of a high and a fixed frequency triangular signals to the current references. New current references are obtained; these are given by the following equations. 


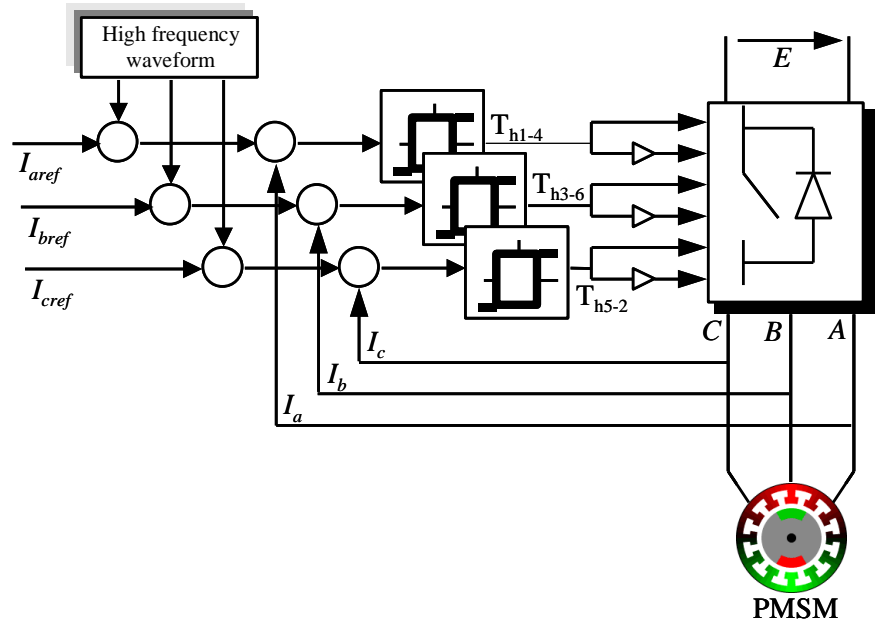

Fig. 5. Hybrid current controller.

$\left\{\begin{array}{l}I_{\text {anref }}=I_{\text {aref }}+I_{t r} \\ I_{b n r e f}=I_{b r e f}+I_{t r} \\ I_{\text {cnref }}=I_{c r e f}+I_{t r}\end{array}\right.$

The new reference signals are compared to the actual currents. Error signals $e_{a}, e_{b}$ and $e_{c}$ then become the inputs to the hysteresis block control as illustrated by Fig. 5 .

$\left\{\begin{array}{l}e_{a}=I_{\text {anref }}-I_{a} \\ e_{b}=I_{\text {bnref }}-I_{b} \\ e_{c}=I_{\text {cnref }}-I_{c}\end{array}\right.$

The upper and lower bounds of the hybrid current controller could then be defined using the new current references and the hysteresis band size $\Delta I$.

$\left\{\begin{array}{l}I_{\text {upper }}=I_{\text {nref }}+\Delta I \\ I_{\text {lower }}=I_{\text {nref }}-\Delta I\end{array}\right.$

As illustrated by Fig. 6, the intersections of $I_{a}$ and $I_{\text {anref }}$ waveforms represent the switching instants. If a fixed frequency is required at the output, two rules must be respected. They are

Rule 1. The switching ON of Th1 is obtained by the intersection of the descending part of the real current with the ascending part of the lower bound of the new current reference.

Rule 2. The switching OFF of Th1 is obtained by the intersection of the ascending part of the real current with the descending part of the upper band limit of the new current reference.

However, in case of a failure to comply with the above rules, two extreme cases will be obtained as depicted in Figs. 7 and 8. Theoretically speaking, the feasibility limits (Fig. 9) of the proposed hybrid current controller are defined by the minimum and maximum angles given by $\left\{\begin{array}{l}\alpha_{\text {min }} \geq \operatorname{atan}\left(2 \Delta I f_{t r}\right) \\ \alpha_{\text {max }} \leq \operatorname{atan}\left[4 f_{t r}\left(A_{t r}+\Delta I\right)\right]\end{array}\right.$

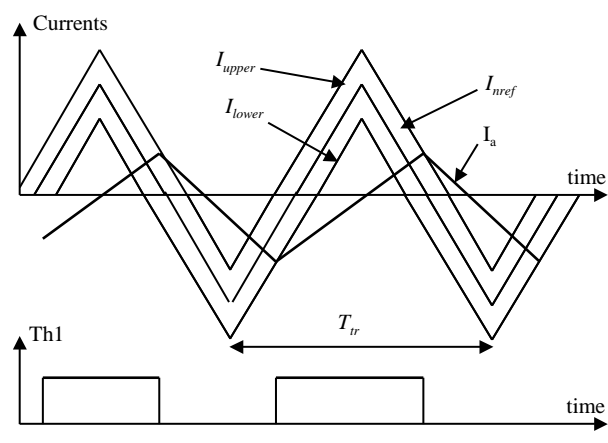

Fig. 6. Design of hybrid controller.

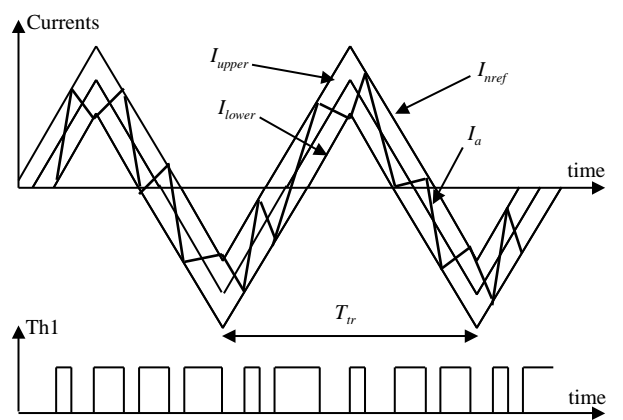

Fig. 7. Extreme case 1: Very high variable switching frequency.

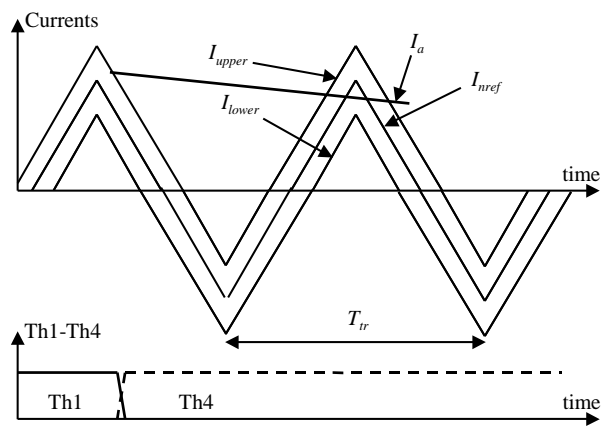

Fig. 8. Extreme case 2: Low and variable switching frequency.
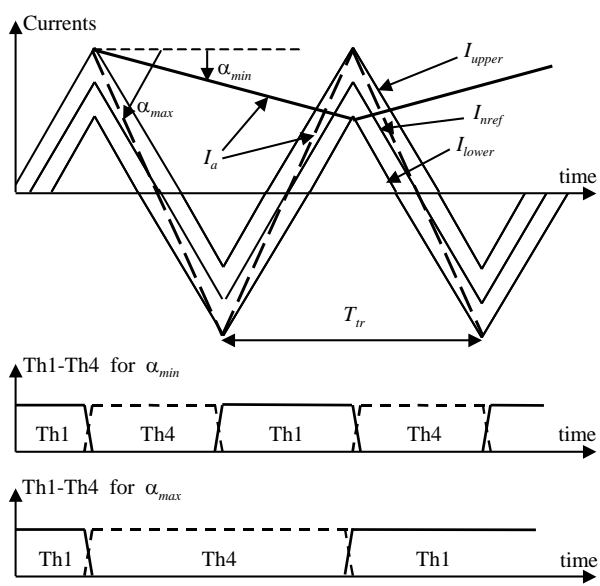

Fig. 9. Feasibility limits of the proposed controller. 
Hence, it is obvious that an exact design of the controller depends on the triangular waveform amplitude and frequency parameters noted respectively $A_{t r}$ and $f_{t r}$, the hysteresis band size $\Delta I$ and the stator time constants $\tau_{d}=L_{d} / R_{s}$ and $\tau_{q}=L_{q} / R_{s}$.

The purpose of the hybrid current controller is to impose a fixed switching frequency to the inverter. As a result, the following expression is always true.

$\max \left(I_{a}\right)-I_{\text {aref }} \leq A_{t r}$

At the upper and lower limits, DC link voltage $E$ may reset the switching frequency.

\section{SIMULATION RESULTS}

The control algorithms of the hysteresis, the ramp comparator and the proposed hybrid controller, for the PMSM drive system, have been developed and implemented using a Matlab/Simulink programming environment. Simulations were carried on a $0.9-\mathrm{kW}$ PMSM whose ratings and parameters are presented in the appendix.

Figure 10 shows the performance of the hybrid current controller for a $150-\mathrm{rad} / \mathrm{sec}$ speed command at a rated load condition $\left(T_{l}=3-\mathrm{N} . \mathrm{m}\right)$. It is worth mentioning that the motor speed accurately tracks the command with no overshoot. During the start up period, the developed torque equals the motor maximum capability. This ensures that the PMSM runs up in the shortest time possible and the developed torque decreases in order to satisfy the applied load torque.

Figure 11 shows the steady state line current and the reference current at various speed references, with a triangular carrier frequency of $1.5-\mathrm{kHz}$. The instantaneous value of the real current is lower than the reference current. The actual current remains at the inferior part of the triangular waveform of the new reference current.

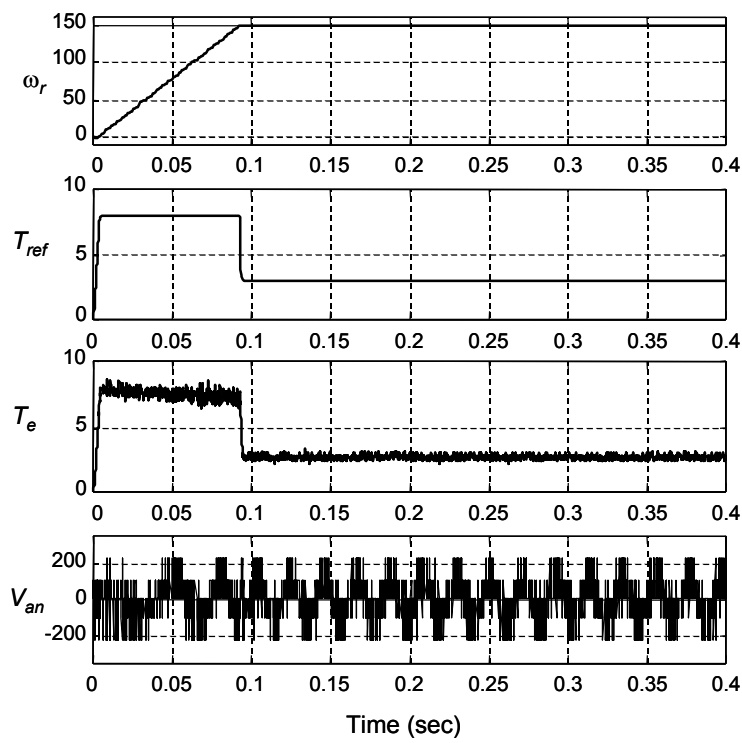

Fig. 10. Hybrid current controller performance.
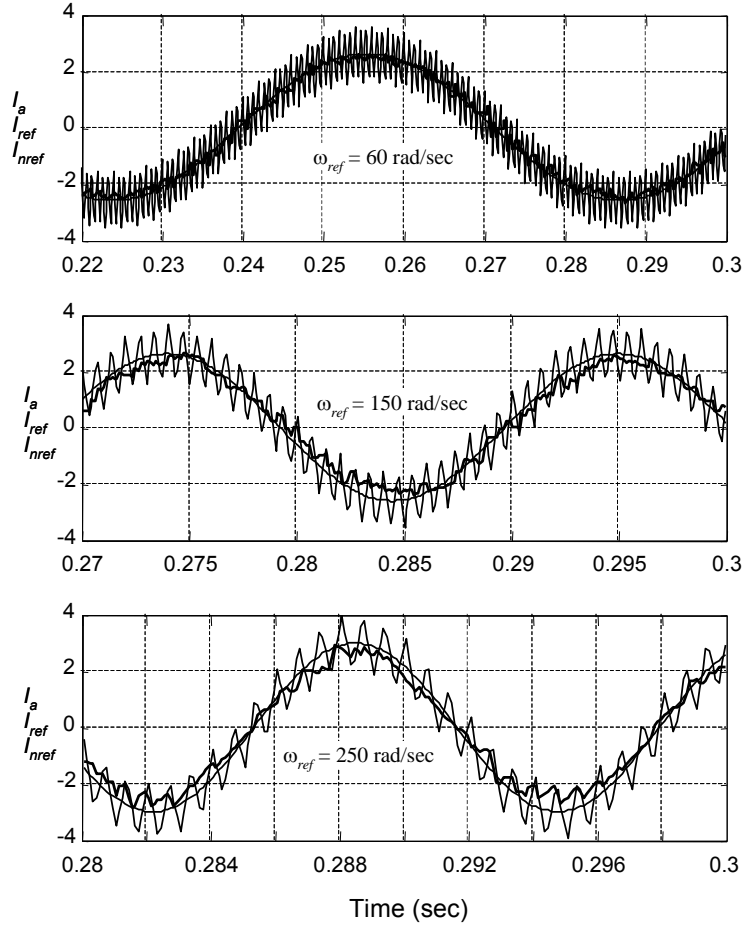

Fig. 11. Speed command effect on the steady state line current.

At a given speed, the error between $I_{a}$ and $I_{\text {aref }}$ increases as the instantaneous value of the real current increases near the peak value of $I_{\text {aref }}$. In the neighborhood of the zero crossingpoint, the difference is small. This is exactly in agreement with the mixed band hysteresis current controller that combines the fixed and the sinusoidal band controllers [23]. In addition, during a single period $T_{t r}$ of the triangular waveform, four changes of current $\mathrm{d} I_{a} / \mathrm{d} t$ are observed. Two changes are caused by phase $A$. The other two are caused by the switching of $B$ and $C$ phases.

Figure 12 shows that phase voltage $V_{a n}$ waveform has the same shape as the one obtained by the ramp comparator controller with five levels: $0, \pm E / 3$ and $\pm 2 E / 3$. For $I_{a} \geq 0$, the $V_{a n}$ corresponding values are obtained by the following applied vectors: $V_{1}(1,0,0), V_{2}(1,1,0), V_{6}(1,0,1)$, and $V_{7}(0,0,0)$.

In case of the fixed band hysteresis controller, even if the regulation requires increased current, it can decrease due to the controllers' interaction. Any voltage vectors $V_{0}$ to $V_{7}$ may be applied. This leads to an irregular waveform of the voltage and a variable switching frequency of the inverter as depicted in Fig. 13. As a result, the harmonics order can reach 80. Figure 14 shows the corresponding harmonic spectrum at a rated load and a rated speed. It is observed that in the case of the hybrid current controller, the harmonic distortion is low as compared to the fixed band hysteresis controller.

The proposed hybrid controller then shows a compromise between the harmonic distortion and the inverter switching frequency. 

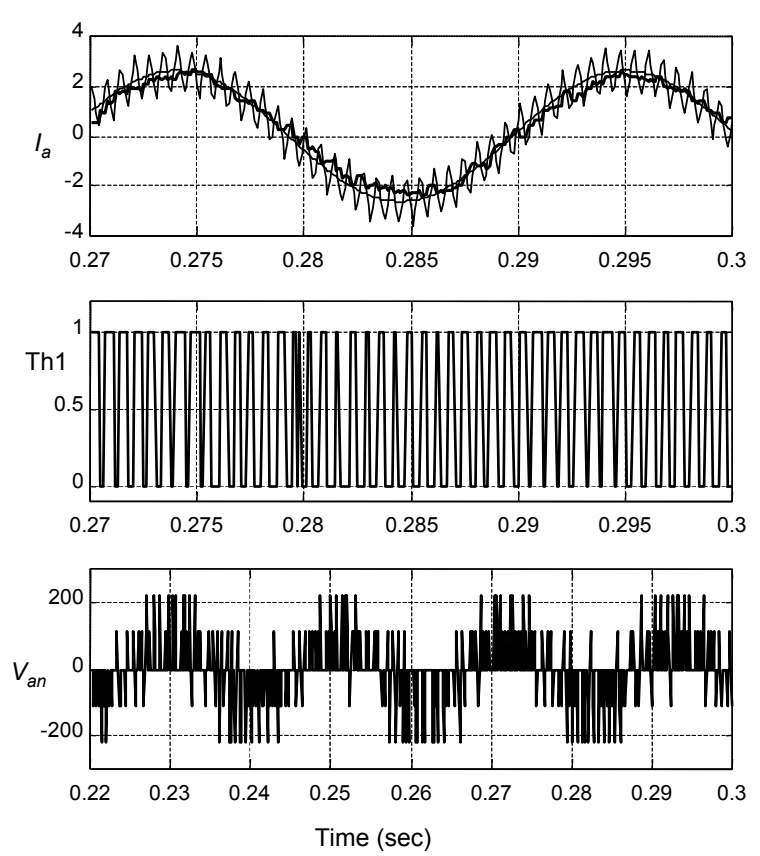

Fig. 12. Hybrid current controller phase voltage.
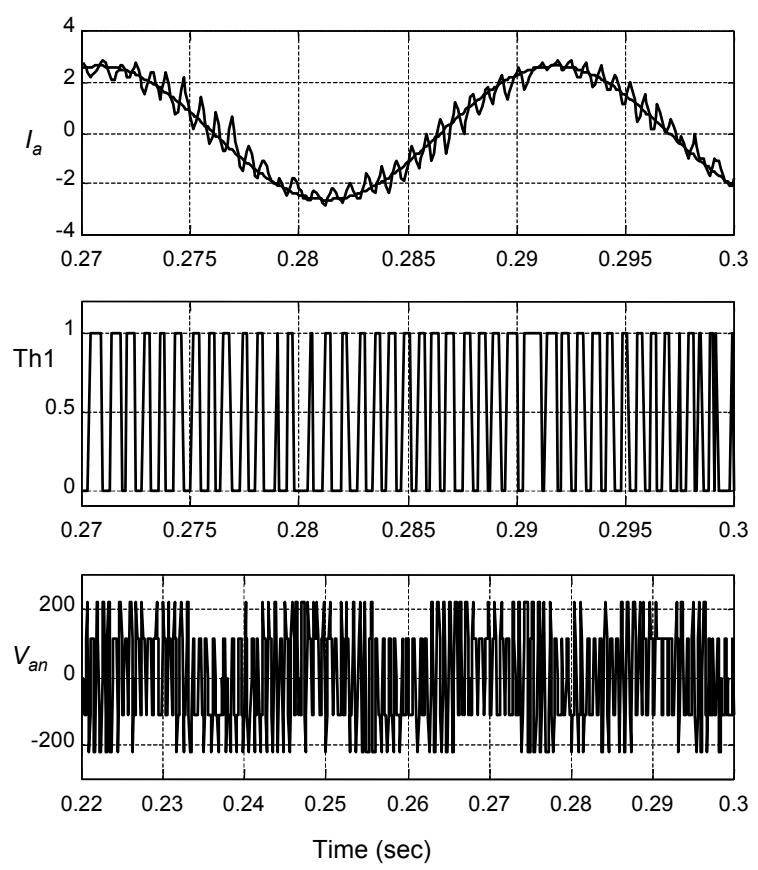

Fig. 13. Fixed band hysteresis current controller.

\section{CONCLUSION}

It has been shown in recent literature that good performance with a high-speed drive may be achieved by using the hysteresis current controller, whereas with a lowspeed drive the ramp comparator controller is the most appropriate one. To take advantage of both controllers, a new hybrid current controller has been proposed and validated by simulations. Detailed analysis of various current controllers for a PMSM drive has been presented.
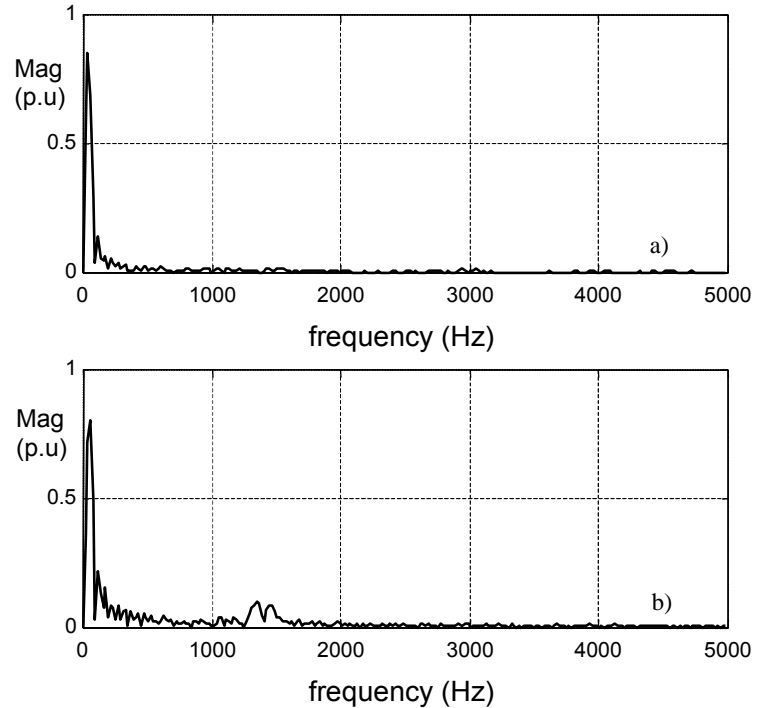

Fig. 14. Stator current FFT. a) Hybrid controller; b) Hysteresis controller.

Comparisons through simulations confirm that the proposed hybrid current controller gives better performance and has the advantage of conceptual simplicity.

In contrast to the classical current control schemes, the following features characterize the proposed hybrid current controller.

- The switching frequency is kept almost constant.

- Regular voltage waveform is given by a limited number of voltage vectors.

- Exact agreement with a mixed band hysteresis controller, defined as a combination of fixed and sinusoidal band hysteresis controllers [24].

- Notable reduction of the distortion components that are concentrated around the near-switching frequency.

APPENDIX

RATED DATA OF THE SimUlated PMSM

\begin{tabular}{llll}
\hline \multirow{2}{*}{ Rated values } & Power & 0.9 & $\mathrm{~kW}$ \\
& Frequency & 50 & $\mathrm{~Hz}$ \\
& Voltage $(\Delta / \mathrm{Y})$ & 220 & $\mathrm{~V}$ \\
& Speed & 1500 & $\mathrm{rpm}$ \\
& Torque & 3 & $\mathrm{~N} \cdot \mathrm{m}$ \\
Rated parameters & Pole pair $\left(n_{p}\right)$ & 2 & \\
& $\phi_{f}$ & 0.314 & $\mathrm{~Wb}$ \\
& $R_{s}$ & 1.5 & $\Omega$ \\
& $L_{d}$ & 0.0349 & $\mathrm{H}$ \\
& $L_{q}$ & 0.0627 & $\mathrm{H}$ \\
& $J$ & 0.003 & $\mathrm{~kg} \cdot \mathrm{m}^{2}$ \\
& $f$ & 0.00008 & $\mathrm{~N} \cdot \mathrm{m} \cdot \mathrm{s}$ \\
& $A_{t r}$ & 1.1 & $\mathrm{~A}$ \\
& $f_{t r}$ & 1.5 & $\mathrm{kHz}$ \\
\hline
\end{tabular}

\section{REFERENCES}

[1] G.R. Slemon, Electric Machines and Drives. Reading, MA (USA): Addison-Wesley, pp. 503-511, 1992.

[2] A. Consoli, G. Scarcella and A. Testa, "Industry application of zerospeed sensorless control techniques for PM synchronous motors," 
IEEE Trans. Industry Applications, vol. 37, n², pp. 513-521, MarchApril 2001.

[3] M. Tursini, F. Parasiliti and D. Zhang, "Real-time gain tuning of PI controllers for high-performance PMSM drives," IEEE Trans. Industry Applications, vol. 38, n 4, pp. 1018-1026, July-August 2002.

[4] S. Morimoto, K. Kawamoto, M. Sanada and Y. Takeda, "Sensorles control strategy for salient-pole PMSM based on extended EMF in rotating reference frame," IEEE Trans. Industry Applications, vol. 38 , $\mathrm{n}^{\circ} 4$, pp. 1054-1061, July-August 2002.

[5] S. Bolognani, M. Zigliotto and M. Zordan, "Extended-range PMSM sensorless speed drive based on stochastic filtering," IEEE Trans. Power Electronics, vol. 16, $\mathrm{n}^{\circ} 1$, pp. 110-117, January 2001.

[6] T.D. Batzel and K.Y. Lee, "Slotless permanent magnet synchronous motor operation without a high resolution rotor angle sensor," IEEE Trans. Energy Conversion, vol. 15, nº, pp. 366-371, December 2000.

[7] J.J. Chen and K.P. Chin, "Automatic flux-weakening control of permanent magnet synchronous motors using a reduced-order controller," IEEE Trans. Power Electronics, vol. 15, n5 5, pp. 881-890, September 2000.

[8] S. Bolognani, R. Oboe and M. Zigliotto, "Sensorless full-digital PMSM drive with EKF estimation of speed and rotor position," IEEE Trans. Industrial Electronics, vol. 46, $\mathrm{n}^{\circ} 1$, pp. 184-191, February 1999.

[9] K.T. Chang, T.S. Low and T.H. Lee, "An optimal speed controller for permanent-magnet synchronous motor drives," IEEE Trans. Industrial Electronics, vol. 41, n5, pp. 503-510, October 1994.

[10] T.M. Jahns, "motion control with permanent magnet machines," Proc. of the IEEE, vol. 82, n ${ }^{\circ}$, August 1994, pp. 1241-1252.

[11] M.P. Kazmierkowski, L. Malesani, "Current control techniques for three phases voltage source PWM converters: A survey," IEEE Trans. Power Electronics, vol. 45, n5, pp. 691-703, October 1998.

[12] D.M. Brod and D.W. Novotny, "Current control of VSI-PWM inverters," IEEE Trans. Industry Applications, vol. 21, n³, pp. 562570, May-June 1986.

[13] S. Ogasawara, M. Nishimura, H. Akagi, A. Nabae and Y. Nakanishi, "A high performance ac servo system with permanent magnet synchronous motors," IEEE Trans. Industrial Electronics, vol. 33, $\mathrm{n}^{\circ} 1$, pp. 87-91, February 1986.

[14] B.K. Bose, "An adaptive hysteresis-band current control technique of a voltage fed PWM inverter for machine drive system," IEEE Trans. Industrial Electronics, vol. 37, n5, pp. 402-408, October 1990.

[15] L. Malesani and P. Tenti, "A novel hysteresis control method for current controlled voltage-source PWM inverters with constan modulation frequency," IEEE Trans. Industry Applications, vol. 26, $\mathrm{n}^{\circ} 1$, pp. 88-92, January-February 1990.

[16] L. Malesani, P. Mattavelli and P. Tomasin, "Improved constantfrequency hysteresis current control of VSI inverters with simple feedforward bandwidth prediction," IEEE Trans. Industry Applications, vol. 33, n5, pp. 1194-1202, September-October 1997.

[17] T.W. Chun and M.K. Choi, "development of adaptive hysteresis band control strategy of PWM inverter with constant switching frequency," in Proceedings of IEEE APEC'1996, San Jose CA (USA), vol. 1, pp. 194-199.

[18] Q. Yao and D.G. Holmes, "A simple novel method for variablehysteresis-band current control of a three phase inverter with constant switching frequency, in Proceedings of the 1993 IEEE IAS Аnпиа Meeting, vol. 2, pp. 1122-1129.

[19] B.J. Kang and C.M. Liaw, "A robust hysteresis current-controlled PWM inverter for linear PMSM driven magnetic suspended positioning system," IEEE Trans. Industrial Electronics, vol. 48, ${ }^{\circ} 5$, pp. 956-967, October 2001

[20] M.N. Uddin, T.S. Radwan, G.H. George and M.A. Rahman, "Performance of current controllers for VSI-fed IPMSM drive," IEEE Trans. Industry Applications, vol. 36, n 6 , pp. 1531-1538, NovemberDecember 2000.

[21] M. Kadjoudj and M.E.H. Benbouzid, "Current control of PMSM fed by two and three levels VSI," in Proceedings of EPE/PEMC'2000, Tuke (Slovakia), vol. 1, pp. 69-74.

[22] K.A. Corzine, "A hysteresis current regulated control for multilevel drives," IEEE Trans. Energy Conversion, vol. 15, n², pp. 169-175, June 2000.
[23] K.M. Rahman, M.R. Khan, M.A. Choudhury and M.A. Rahman, "Variable Band hysteresis current controllers for PWM VSI," IEEE Trans. Power Electronics, vol. 12, nº, pp. 964-970, November 1997.

[24] A.J. Tripathi and P.C. Sen, "Comparative analysis of fixed and sinusoidal band hysteresis current controllers for voltage source inverters," IEEE Trans. Industrial Electronics, vol. 39, n¹, pp. 63-73, February 1992.

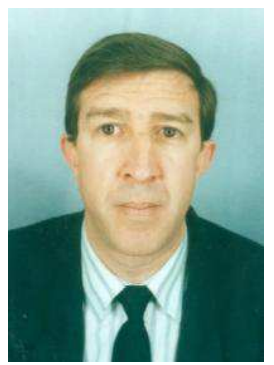

Mohamed KADJOUDJ was born in Batna Algeria, in 1964. He received the B.Sc. and M.Sc degrees both in Electrical Engineering, from the University of Batna, Algeria, in 1988 and 1992 respectively.

After graduation, he joined the University of Batna, Algeria, where he is a Teaching Assistant at the Electrical Engineering Institute. He is currently working towards a Ph.D. thesis on the intelligent control of permanent magnet synchronous motors.

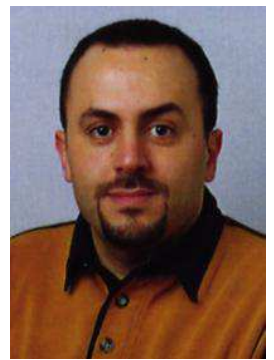

Mohamed El Hachemi BENBOUZID (S'92M'94-SM'98) was born in Batna, Algeria, in 1968 He received the B.Sc. degree in Electrical Engineering, in 1990, from the Electrical Engineering Institute of Batna University, Algeria; the M.Sc. and Ph.D. degrees both in Electrical and Computer Engineering, from the National Polytechnic Institute of Grenoble, France, in 1991 and 1994 respectively.

After graduation, he joined the University of Picardie "Jules Verne", France, where he is an Associate Professor of Electrical and Compute Engineering at the Professional Institute of Amiens. In November 2001, he received the "Habilitation à Diriger des Recherches" degree from the University of Picardie "Jules Verne". His current research interests include electric machines and drives control and diagnosis

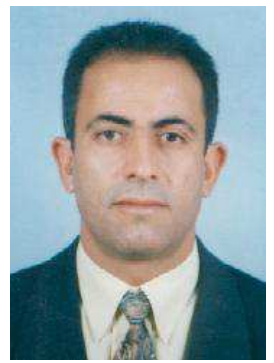

Chawki GHENNAI was born in Batna, Algeria, in 1963. He received the B.Sc. degree in Electrical Engineering from the University of Batna, Algeria, in 1988, and the Ph.D. degree in Electronic and Electrical Engineering from the University of Leeds, UK, in 1993. After graduation, he spent three years (1993-1996) as a lecturer at the Higher Institute of Industry, Misurata, Libya. He is currently a Lecturer at the Electrical Engineering Institute, University of Batna, where he is leading a research project in modeling and simulation of power semiconductor devices and computer-aided design of electronic converters. His research interests include computer-aided design of microwave solid-state oscillators, modelling and simulation of power semiconductor devices and power electronics converters.

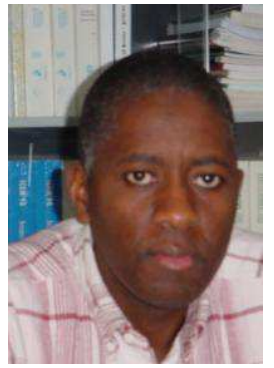

Demba DIALLO (M'99) was born in Dakar, Senegal, in 1966. He received the M.Sc. and Ph.D. degrees both in Electrical and Computer Engineering, from the National Polytechnic Institute of Grenoble, France, in 1990 and 1993 respectively.

From 1994 to 1999, he worked as a Research Engineer in the Laboratoire d'Electrotechnique de Grenoble, France, on electrical drives and active filters (hardware and software). In 1999 he joined the University of Picardie "Jules Verne" as an Associate Professor of Electrical engineering. His current area of research includes advanced control techniques and diagnosis in the field of ac drives. 